\title{
Onboarding new hires: recognising mutual learning opportunities
}

\author{
Debora Jeske
School of Applied Psychology, University College Cork, Cork, Ireland, and \\ Debora Jeske
School of Applied Psychology, University College Cork, Cork, Ireland, and \\ Deborah Olson \\ College of Business and Public Management, \\ University of La Verne, La Verne, California, USA
}

\begin{abstract}
Purpose - The onboarding stage of new hires represents a unique opportunity for mutual learning between the new hires and the organisation regardless of the company size. The current paper aims to address these learning opportunities.

Design/methodology/approach - The authors reflect on current practice, draw on recent literature and their experience with recruitment and selection processes in the industry to generate new insights and identify opportunities for practitioners and new hires alike.

Findings - Today's new hires expect onboarding experiences that allow for a much greater degree of flexibility, customisation and personalisation. Similarly, many new hires expect hiring, onboarding, and learning and development to be interconnected to generate new learning and career opportunities. However, these expectations require changes in the way in which onboarding is implemented, evaluated and connected to other human resource practices, specifically with the dramatic (and successful) increase in remote work arrangements in 2020 in response to the global impact of the pandemic.

Originality/value - The current paper provides readers with an overview of potential learning opportunities, outlines specific success factors and highlights a variety of pointers for practice and further professional development.
\end{abstract}

Keywords Onboarding, Induction, Proactivity, Learning, Attraction, Selection, Retention

Paper type Viewpoint

\section{Introduction}

Onboarding represents a meaningful transition for employees as they enter new work environments, become part of teams and take on new responsibilities (Adler and Castro, 2019). It introduces new hires to team and organisational practices, processes, policies, and values to support the adjustment and positive early experiences of new hires (Klein and Polin, 2012; Caldwell and Peters, 2018). These transitions can vary in terms of content, formality, timing, budgeting, and customisation vs. standardisation. While some transitions are more formal, featuring the paperwork and the necessary training to succeed in the role (Adler and Castro, 2019), more informal onboarding practices are also being employed that are more individualised and less structured.

Onboarding also shares a significant overlap with induction, which can be defined as "any arrangement made to familiarise the new employee with the organisation, safety rules, general conditions of employment and the work of the section or department in which they are employed" (Skeats, 1991, p. 16). Socialisation is another important concept that is often mentioned in connection to both induction and onboarding. "Organizational socialization is

(C) Debora Jeske and Deborah Olson. Published in Journal of Work-Applied Management. Published by Emerald Publishing Limited. This article is published under the Creative Commons Attribution (CC BY 4.0) licence. Anyone may reproduce, distribute, translate and create derivative works of this article (for both commercial and non-commercial purposes), subject to full attribution to the original publication and authors. The full terms of this licence may be seen at http://creativecommons.org/licences/by/4.0/ legalcode

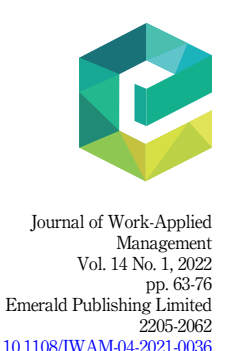

DOI 10.1108/JWAM-04-2021-0036 
JWAM

14,1 the process through which newcomers learn the requisite social and task knowledge in order to resolve role uncertainty and become organizational insiders" (Kowtha, 2018, p. 87).

Onboarding today often includes both the traditional induction elements and the socialisation components. In the last two decades, socialisation and the use of various tactics have become more and more important in onboarding (e.g. Kowtha, 2018) expanding traditional compliance-oriented onboarding processes accordingly (see Benzinger, 2016; Chao et al., 1994). This means key informational aspects are also combined with key activities to support employees' development of interpersonal connections in order to also introduce them to information networks. These more formal activities are usually complemented by informal activities that usually include meetings and social activities involving the various actors within the organisation that the new hire will work with. This frequently includes internal representatives such as the supervisors, team members, senior management representatives, human resource professionals, mentors, as well as external stakeholders such as major clients and customers (e.g. Bhakta and Medina, 2021; Stewart et al., 2021).

The move to more online onboarding has not just changed how and by whom information is communicated (e.g. via video rather than in-person; Morrison, 2021; Rodeghero et al., 2021). What is more, the importance of team building, social bonding and the need to be inclusive for candidates from diverse backgrounds has gained more recognition as critical onboarding aspects in the last two years (Brown, 2021; Rodeghero et al., 2021; Stewart et al., 2021).

There is a clear need to re-focus on and consider re-designing the now often online onboarding processes (Stewart et al., 2021). Shufutinsky and Cox (2019) found that individuals who were not satisfied with the onboarding process within the first few months left the organisation within one year of hire. This concern applies to not just on-site but also online onboarding (see also Moran, 2019). The recent move to online onboarding and remote work in many sectors emphasises the significance of designing and implementing systematic plans for onboarding (e.g., Stewart et al., 2021). Onboarding needs to connect to the selection processes, build commitment, consider the well-being and social connection and identify new ways that enable particularly remote and junior hires to contribute to achieving goals.

\section{Onboarding as a source of learning opportunities}

Such situations represent unique challenges as well as learning opportunities, both for the individuals transitioning into new roles and the teams and organisations they are joining (e.g. Morrison, 2021). Learning opportunities arise in numerous ways (see Table 1 for an overview).

\section{Employee and team learning}

The onboarding experience sets the stage for new hires' expectations about how to behave, connect to other staff members and succeed in the new role. The features, highlights and nature of the onboarding experience serve as signals to the new hire as to what the employer prioritises, what they value and how the new hire will fit into their teams, mission and plans (Adler and Castro, 2019). These signals are sent by peers, managers and professional representatives (Gherardi and Perrotta, 2010; Rodeghero et al., 2021).

Employees' first experiences of onboarding can also shape their readiness and ability to adjust in the future when they are joining new projects or teams. Organisations need to consistently review and evaluate the onboarding experiences of their hires in order to optimise, improve and refine their onboarding processes over time as expectations on new hires, their teams, and the organisation as a whole change (see also Karambelkar and Bhattacharya, 2017). This is essential in the context of increasing remote work and the 


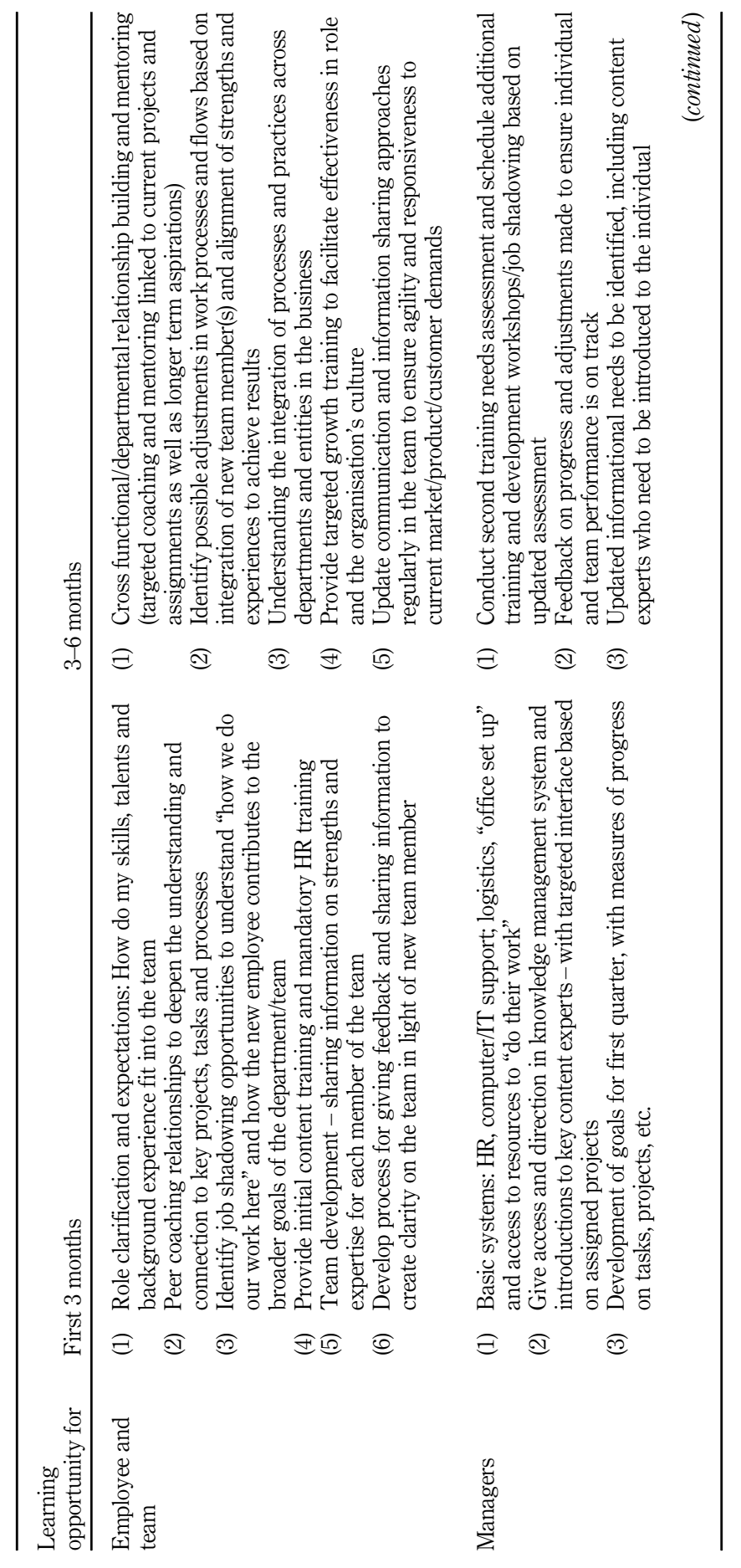

Onboarding new hires

65

Table 1. Considerations for onboarding: continuous learning and growth 
JWAM
14,1

66
营

일

क

ฮิ

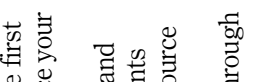

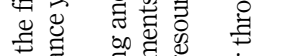

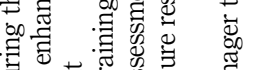

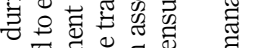

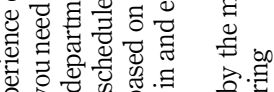

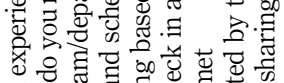

5)

군

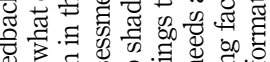

心

o.

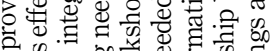

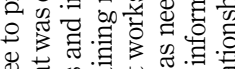

\&

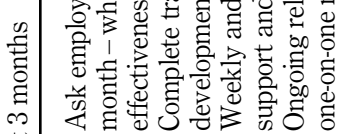

$\stackrel{m}{*}$

ล $\overparen{ } \circledast$

Ð

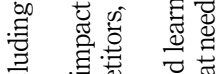

要 票

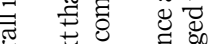

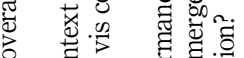

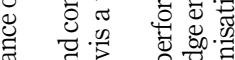

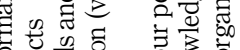

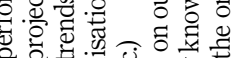

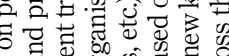

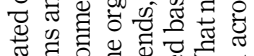

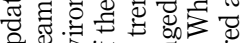

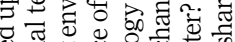

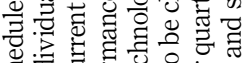

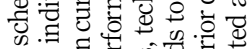

용 5

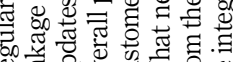

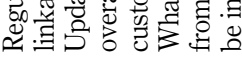

ฮ ब

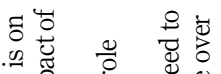

骂. 苨

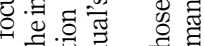

专焉

荡

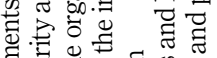

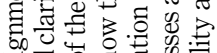

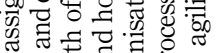

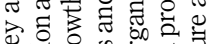

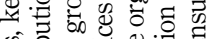

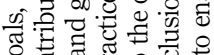

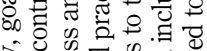

定.

तٓ

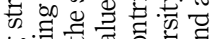

on. एँ

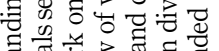

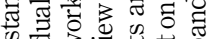

可.

క.

อ ลิ ลำ

Table 1.

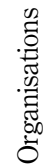


different needs based on the individuals and the roles they fill (see also Bhakta and Medina, 2021; Stewart et al., 2021; Rodeghero et al., 2021).

Furthermore, onboarding new team members can also influence the emotional tone and interaction between existing team members. This, in turn, may impact the emotional culture within a team, that is, the affective experience of a team (Adler and Castro, 2019). As a result, employee learning is also prompted by involving teams in the onboarding process. Horstmeier et al. (2016) noted that social support also fostered greater team identification. Similarly, as our practical experience in industry has shown, the onboarding may also trigger new learning processes among existing team members who need to change and shift their own roles and responsibilities in response to the new team members taking on their or interconnected roles.
Onboarding new hires

\section{Managerial support and learning}

Managerial competencies and information sharing play a critical role when a new team member is introduced to a new team. In addition, manager's perceptions of a new hires' proactive behaviours and adjustment also matters. For example, Ellis et al. (2017) found that new hires report less anxiety when their supervisors share more information and offer more support; they mastered new tasks more quickly, showed improved performance, and lower turnover intention. An assessment of new hires experience throughout the interview and onboarding process is essential, particularly when the entire selection process may have occurred remotely as during the 2020 global pandemic (Bhakta and Medina, 2021; Roghedero et al., 2021). Managers need to be aware of the impact of the loss of face-to-face experience during the selection process and ask for feedback from selected candidates regarding their specific preferences and needs during the onboarding process to ensure that it is customised and personalised.

Based on our own industry experience, we also found that asking new hires directly for their feedback to craft the onboarding process can generate important learning insights for the managers tasked with onboarding new hires with different needs (see also Stewart et al., 2021), different cultural and ethnic backgrounds (in line with diversity and inclusion activities), and different future areas of responsibility. In addition, involving top management and employees in onboarding rounds ensures that a bi-directional conversation is established and reinforced as the relationship with the new hire in developing. Such conversations during onboarding can update managers and employees around novel developments that might be shaping the hiring and onboarding processes and prevent or minimise the impact of "ghosting" whereby individuals who accept job offers never show up for the first day (Moran, 2019).

In addition, these conversations can provide a sense of which resources are needed to improve the experience of new hires, their teams, and supervisors. Perceived organisational support, for example, has also been argued to be an important requirement so that supervisors have the time and resources to support the work adjustment of new hires (Jokisaari and Vuori, 2018). Examples here include time and resources that enable supervisors to coach their new hires. Furthermore, feedback from new hires, and emerging expectations from new talent, can be helpful to update recruitment, selection, and onboarding practices as well as indicate new resource needs to meet new expectations and changes reported by the new hires (see also Chillakuri, 2020).

\section{Organisational learning}

To provide new hires with an adequate understanding of the organisation as a system, onboarding usually includes a variety of information and a number of interactional opportunities for new hires. However, the opportunity that onboarding represents for businesses is not recognised as readily. Sprogoe and Elkjaer (2010, p. 140) accordingly raised the challenge that organisations want "organizational change through recruiting newcomers 
JWAM

14,1

68

but inducting in ways in which there is little room for change." However, the design, updating and evaluation of onboarding processes with the various stakeholders in and outside the business can generate new opportunities for learning. We highlight three perspectives here.

At a very basic level, hires bring in new expertise and perspectives that can complement but also challenge - existing values and approaches. Indeed, "onboarding does not just have to be the organization's inculcating new employees in corporate culture. Rather, an individual's entry into the organization can potentially influence that organization" (Adler and Castro, 2019, p. 109). New hires can provide valuable perspectives to recraft the onboarding process.

Bhakta and Medina (2021) suggest that the process can be recrafted to include three phases: preboarding, orientation, and onboarding especially when the selection processes are entirely virtual with no face-to-face contact. Adapting approaches that were created and extended during the global pandemic, shows candidates that thoughtful consideration is being given to them to build relationships with multiple people in the organisation, particularly candidates who may have other options they are pursuing. For example, including more people in the recruiting process who reach out and share information and address questions from the top candidates demonstrates that the team and hiring manager are investing time and showing interest in the top candidates.

Once new hires complete the orientation and onboarding process, they can serve as internal consultants on processes - bringing in fresh expertise and eyes to existing processes before they have become accustomed to routines, language, and ways of thinking. Their energy and less conventional thinking can also facilitate organisational renewal and stimulate momentum for change (Sprogoe and Elkjaer, 2010). In addition, by matching hires and long-term employees along shared areas of interest, employers can also set up mutual or reverse mentoring (from new hires to the existing workforce and vis-à-vis; see also Garg et al., 2021).

Especially when businesses undergo transitions of their own (e.g. due to restructuring, change management, mergers, and acquisitions and similar), new entries coming into a workplace can potentially shape and affect the organisations in ways that are less impactful during relatively stable times. In addition, senior hires can influence their own onboarding experience using the events that are often part of these transitions, set the tone and shape new expectations for the existing workforce by commenting on the plans and aspirations for the business under this new leadership. As a result, employee onboarding can also be a trigger and impetus for learning - increasing situational awareness, creating change readiness, and highlight potential barriers to change (e.g. such as existing routines, habits, and outdated values that anchor the organisation in the past rather than in the future).

\section{Success factors for individual onboarding}

Most organisations initiate onboarding immediately when a new hire starts. However, some businesses have recognised the importance of starting with onboarding shortly after hiring (pre-boarding) to keep the new hires motivated and engaged (e.g. Bhakta and Medina, 2021; Zung, 2020). This is particularly important when employees' have lengthy notice periods and competition for their skills is high. Many small companies will organise their onboarding practice as an ad hoc problem-solving task rather than investing time into a practice (Mulders et al., 2010). However, the need to provide customised onboarding recognises that new hire's transitions may vary and depend on the individual, the nature of their contract, the role, and industry in question (Karambelkar and Bhattacharya, 2017). As a result, organisational size and resources are not by default absolute determinants of effective onboarding. Indeed, a number of success strategies involving all stakeholders can be applied even in small workplaces to improve the onboarding experience, work adjustment, and learning of their new hires. In this section, we focus on three examples which outline potential success factors for individual onboarding. 
Proactivity of new hires and managers

Transitions can be challenging experiences, especially for those who are transitioning into new functions, take on cross-functional roles, or join a very fast-paced work environment. The allocation of mentors, buddies and coaches is a good way to support these more individualised forms of onboarding (Bhakta and Medina, 2021; Caldwell and Peters, 2018; Karambelkar and Bhattacharya, 2017). Similarly, actions to foster team identification may be helpful (see also Horstmeier et al., 2016; Rodeghero et al., 2021). Proactive managers who are proactively sharing information, encouraging peer coaching and job shadowing facilitate the success of onboarding (Dekas, 2013).

These approaches are particularly relevant in the fast-changing workplace as mentors and buddies can be important channels of support and appreciation (Bhakta and Medina, 2021). However, their role is not just essential during the initial periods of time (e.g. probation) but also other phases such as shifts in projects and departmental transitions (which require project and additional departmental onboarding). The availability of mentors and buddies can reduce employee stress initially, but these connections can also be essential to assist and maintain engagement among new hires over time, even after the official onboarding comes to an end (Cattermole, 2019).

\section{A multi-stakeholder effort}

Onboarding is both a human resource practice but also a process of steps. As the concept of onboarding has been expanded, so has the understanding regarding the importance of involving various stakeholders early on. Cesário and Chambel (2019), for example, propose that onboarding should involve three forms of welcomes to build commitment and work engagement. These authors suggest that the corporate welcome essentially serves as a means to provide new hires with information about the organisational rules, history, and role specifics to ensure that the new hire has a good understanding of the basics. The second dimension is the management welcome which concerns the interactions with, and support provided by the supervisors and managers tasked with supporting new hires (see also Ellis et al., 2017). And third, Cesário and Chambel (2019) note the importance of co-worker welcome. This dimension focuses on interactions with co-workers that also reduce potential anxieties and resource gaps that support the integration of new hires (see also Bhakta and Medina, 2021). Furthermore, interactions with sponsors, customers, and clients can further give new hires a better sense of their roles, responsibilities, and organisational priorities.

\section{Bi-directional flow of information}

By engaging in bi-directional knowledge exchange, organisational representatives can also get a sense of the new expertise that becomes available when a new hire joins the business. The delegation of tasks to newcomers has also been associated with newcomers gaining more role clarity and a greater degree of organisational knowledge (Jokisaari and Vuori, 2018). A purposeful exploration of their skills and talent can also - if tied to the company's knowledge management - also be brought to the attention of the broader workforce. At the moment, few workplaces explore the connection between onboarding, continuous learning, and organisational development (Cattermole, 2019; Stewart et al., 2021). When the onboarding experiences focuses on individual's authentic expression and highlights how their strengths are valued, turnover intention can also be reduced and performance increased. Many hires also want to understand not only the bigger picture at work, but also gain a sense of meaning from work (Chillakuri, 2020).

Onboarding can be combined with a number of activities (see also Stewart et al., 2021). This includes connecting onboarding with learning and development, leadership development, and consulting. All these steps go beyond traditional onboarding and can

Onboarding new hires 
JWAM

14,1

70

make a significant difference to the experience and long-term commitment of new hires. The role of managers in setting the groundwork for this exchange, employees' development and team-oriented collaboration will be pivotal. The use of information from new hires in the development of human resource strategies can further ensure that onboarding practices are updated, competitive, and effective - and that the onboarding experiences are setting an excellent foundation for future practices, programs, and processes.

\section{Clarifying the employee value proposition during onboarding}

New hires today have high expectations regarding their entry experience and the role that the new appointment may play in their future career. Clarifying the employee value proposition is therefore becoming more and more important. While pay remains an important motivator, the access to new learning and development opportunity is a close second. In response, several employers emphasise the meaningfulness of the new role (Chillakuri, 2020), as well as the training or coaching benefits that new hires acquire (especially when this training is unique to the industry or company). Any conversation about learning and development opportunities during onboarding should be prompts for further developmental conversations with the new hire. Given the choices that talent now have in the increasingly remote and global world, it will be critical to identify those individual retention factors that will increase mutual commitment whereby the individual experiences growth and development and the organisation is positively impacted by goals and results achieved over time.

\section{The onboarding experience: immediate costs vs. long-term benefits}

The costs and time investment of onboarding can often raise the eyebrows of management. However, several arguments can be put forward that will outline the merit of immediate costs in favour of long-term benefits. A useful lens through which one can analyse the costs vs. benefits is the Attraction-Selection-Attrition (ASA) model by Schneider (1987). According to this model, the processes associated with the attraction of candidates to the organisation, the selection of specific hires, and the attrition of these hires will contribute to the characteristics of the workforce over time.

In essence, potential candidates will be attracted to employers that feature similar values, working models, and priorities. Similarly, many candidates will accept job offers when they also feel that the employer will offer them opportunities of interest to them. And finally, many new hires leave an employer when they subsequently feel they do not share the same goals, values, and priorities necessary for them to fit in with their teams and the organisation (Shufutinsky and Cox, 2019). The ASA model has been used in a variety of studies that examined the intention of potential hires to join a company and communities (e.g. Harris and Pattie, 2020; Link and Jeske, 2017). We argue further that this model can be helpful as a basic framework to discuss onboarding experiences and outcomes for organisations as well.

\section{Connecting onboarding to the ASA model}

Candidates are often attracted to organisations due to the signals shared by the employers online during their recruitment process (Gregory et al., 2013). Their perceived fit to others - these days readily assessable using platforms such as LinkedIn - can increase the attractiveness of an employer. Experts and thought leaders can be an important source of attraction for potential candidates (Link and Jeske, 2017), while organisational leadership and reputation can further increase the attractiveness for candidates. These impressions can be maintained or undermined during the recruitment and selection process, but most certainly also during the onboarding experience. First impressions, first interactions, and networking prior to, during, and after onboarding all affect the perceived attractiveness of new roles, team, and organisation.

What is more, these first experiences are also the first test of the psychological contract (Caldwell and Peters, 2018). These contracts are usually unwritten, and capture expected 
reciprocal relationships (Rousseau, 1995). This also means that organisations have to work towards maintaining the attractiveness of the experience by ensuring that new hires' personal values, preferences, and priorities are indeed well aligned with those of the role. Paying attention to signals from new candidates for employment before their entry into the organisation can therefore be helpful to identify those potential hires whose motivation or availability to join the business might be affected by personal or other events. Doing so does require time and continuous digital networking on the part of the organisation before the candidate even starts employment. Cutting through the noise may be difficult, but such efforts are worthwhile to retain and raise the commitment of talent (Chamorro-Premuzic et al., 2016). This means that organisational attractiveness is an issue that is not closed just because a hire agrees to sign a contract. The hiring, onboarding and in-role experience will all continuously shape organisation attractiveness, requiring a more integrated approach to handling hiring, onboarding, and learning and development.

More engagement can be created when new hires can influence and shape their own onboarding experience. When onboarding is connected to personal development plans (e.g. Chillakuri, 2020), many hires will feel more engaged and reassured that their own selection choice (i.e. accepting the job offer) was the right one. Pre-onboarding activities upon hiring are essential to keep new hires interested and committed to joining their new employer. Particularly at the beginning, sudden departures of new hires can be very costly for the organisation and detrimental to the team and organisations that had expected to work with the new hire.

In some case, despite all effort, new hires leave the workplace shortly after they start a new job (Ellis et al., 2017). This attrition often happens during or shortly after onboarding (Shufutinsky and Cox, 2019). Efforts to assess organisational attractiveness as judged by new hires, and honest discussions around their rationale for opting to take up new positions (their own selection choice) during the selection stage can help to identify those candidates who may not necessarily share the same values as the employer. However, none of these steps will prevent attrition entirely upon organisational entry. Onboarding again can play a role here to help new hires to accurately interpret new signals they receive from organisational representatives, clarify potential misunderstandings, while also leaving room for the discussion of divergent expectations. However, most onboarding practices do not address these aspects head on. Highly structured, impersonal, and formal onboarding experiences lack opportunities for such frank conversations. One issue that can contribute to potentially misleading signals being sent is the fact that many larger onboarding programs are run by junior hires and interns. When top managers, learning and development professionals and mentors are featured, they often only partake in part of the program. Nor are many companies paying attention to the need to be more inclusive in their onboarding (although this is slowly changing) as many organisations feature specific age groups and representatives from majority groups alone.

This means that many new hires form their first impressions about their future within the organisation by interacting with some of the least experienced, though often enthusiastic, staff who may not reflect the diversity of talent, perspectives, and expertise represented in the company. What is more, many onboarding programs are so generic that little attention is paid to the individual hires. Their expectations and expected value propositions may only be discussed in broad strokes, if at all (Steer, 2013). Many employers miss out on a valuable opportunity to reduce early attrition during or shortly after onboarding, by not considering the role of onboarding experiencing (Bauer, 2010). Previous work has already shown that relational investment and communication can be critical for the relationship with and retention of virtual interns (Jeske and Axtell, 2018). It is important to review how onboarding can prevent potential attrition of new hires - by assessing which signals are being sent through the organisers, the interactions, and the representatives that show up (or do not). In
Onboarding new hires 
JWAM

14,1

summary then, a focus on the short-term needs of the employer and costs vs. the long-term interests of employees will risk undermining the success of onboarding, reducing the benefits, and potentially mutually rewarding learning opportunities for both new hires and the organisation.

\section{Discussion and implications for practice}

Onboarding managers still face several challenges. One example concerns the characteristics of those who are onboarding (e.g. the diversity of candidates). This includes neurodiverse candidates and those coming from very different backgrounds than most of the employees hired to date. Focusing on differences emphasises the importance of managers and team members attention to the well-being of everyone (Stewart et al., 2021). Asking questions to understand and accommodate the unique challenges each team member faces becomes a baseline consideration for facilitating diversity and inclusion. The type of support, mentoring, and information sharing needed to successfully complete work and achieve important organisational goals needs to be fully discussed and plans created to provide that support. These actions reduce the stress experienced by the individual allowing each to complete the work and assignments in ways that optimise their unique talents and acknowledges that different approaches are valued and supported (see also Stewart et al., 2021).

Another example concerns the delivery modus (digital, in-person, asynchronous vs. synchronous) and reach of onboarding practices. The move to remote and hybrid working further challenge established practices and create the need for reinvention and cooperation across traditional boundaries within organisations (e.g. Caliguiri et al., 2020; Gratton, 2021; Kniffin et al., 2021). In the networked world, one-way communication patterns and one-sizefits-all assumptions during onboarding are no longer fit for purpose. Today's onboarding needs to address several challenges: From the information and social needs of new hires and their teams to the role specifics and person-specific developmental needs that should be assessed and addressed at the onboarding stage. Onboarding today is about connecting new hires across networks, departments, and locations. A few pointers further outline areas for discussion and consideration.

The need to provide all employees with a quality and ideally comparable experience often needs to be compared with the requirement to offer more individualised onboarding that also addresses the unique requirements of the new hire and role. One approach here is to split onboarding into two segments. The first segment could be dedicated to communicating the general organisational mission, values, cultural values, and priorities to ensure everybody has the same information about these key aspects. Messages from top management, introductions to support groups, procedures are all aspects that could delivered digitally using numerous platforms. The second segment could be focused on the individualised messaging, role specifics, team introductions and supervisory interactions around expectation management, performance management, learning and development. This means that the challenge of providing a similar, yet customised experience is not insurmountable.

But we would be amiss if we did not mention some key challenges and areas that require more experimentation and reflection in practice. Onboarding practices often vary across organisations but also departments, countries, professional groups, and industries. What is more, onboarding practices and processes often vary depending on the type of employment contract. Benzinger (2016) noted in a study with German employees that more structured and formalised onboarding was provided to those permanent hires, while a more individualised approach was chosen for contingent workers. However, it may be worth considering how to provide similar comprehensive onboarding when contingent workers are considered a talent pool for permanent future hiring to ensure that this talent pool has a similar understanding of organisational values, procedures, and expectations. To date, anecdotes suggest that many 
businesses skip onboarding for those employees who move from temporary to permanent roles - missing out on an important opportunity to create the same entry experience for these employees. Few employers to date onboard their gig workers (but see Odom, 2018), even though these workers may represent a potential talent pool for permanent hires at a later stage.

Another wrinkle in practice is that onboarding is a process that is not finite-even though many onboarding processes are often treated as such. Given today's changing work environment, the move to agile working, project-based and self-organising teams, the key sentiments of onboarding remain important through the working life of employees. As a result, some experts also advise that change management models are useful frameworks for the development of onboarding processes (Karambelkar and Bhattacharya, 2017). There is also a recognition that the coaching and learning and development resources provided to employees need to match these developments to ensure that employees can be productive contributors as their roles and responsibilities shift during their lifetime with the organisation (Caldwell and Peters, 2018). While many employers are recognising these interconnections in the way they are approaching onboarding, there is still room for improvement, especially in the remote workplace.

\section{Practical and reader recommendations}

In this paper, we focused specifically on general framework for onboarding of employees. Some onboarding focuses on new professionals or graduates by professionals. In those onboarding scenarios, professional identity of the hires plays an important role in the process. Such onboarding is discussed in more detailed in Rodeghero et al. (2021), Gherardi and Perrotta (2010), Hawse and Wood (2019), Horstmeier et al. (2016). The onboarding challenges and good onboarding practices for expatriates and host nationals are outlined in several additional publications (e.g. Guðmundsdóttir and Lundbergsdóttir, 2016; Tharenou and Kulik, 2020). An overview of one alternative approach to onboarding involving co-created induction and education-to-work transitions is available in the paper by Hawse and Wood (2019).

A few additional resources are available to practitioners interested in familiarising themselves with some of the more recent onboarding literature. Adler and Castro (2019) present an occupational health and well-being model that considers the role of individual factors such as coping strategies and preferences as well as organisational factors in relation to the transitions that employees experience, from onboarding to offboarding. Not all new hires will learn similarly well in given situations, so customising onboarding can be essential in the design of onboarding (Karambelkar and Bhattacharya, 2017; Stewart et al., 2021). Some customisations may also be required depending on the experience and seniority of those being onboarded. For those hiring graduates with minimal work experience, Chillakuri (2020) outlines a number of recommendations for employers onboarding young generation $Z$ hires while Kowtha (2018) discusses the role of prior work experience as a moderator in the relationship between socialisation and work adjustment, specifically commitment, role clarity and conflict.

Onboarding can be a stressful experience for the new hire but also the employer. Cesário and Chambel (2019) produced the appropriate measures for internal surveys to assess the effectiveness of onboarding based on new hires experience with the corporate, managerial and co-worker welcome they received. Their subscale for the measurement of how new hires rate their co-worker welcome also captures new hires' evaluation of the support they received from co-workers and the extent to which this support reduced doubts and to reduce concerns of job inadequacy. In an age where many workers work remotely, share their workspaces with others, and need to learn new skills even faster than before, employers are wise to consider employee needs and uncertainty. Using measures such as those provided by Cesário and Chambel (2019) can be helpful for practitioners seeking to assess new hires' experience with onboarding. Furthermore, such steps allow human resource professionals to audit the
Onboarding new hires 
JWAM

14,1

effectiveness of onboarding practices and identify additional support needs - before they impact the performance of new hires.

\section{Conclusion}

As the world of work is pivoting in response to global changes and challenges, it is noteworthy that onboarding practices have not necessarily adjusted to keep pace with significant changes in work processes. Many companies continue to roll out generic programs that are not tailored, customised, or effectively linked to other human resource practices. By failing to recognise these trends, many organisations continue to experience retention issues, often loosing opportunity to gain their commitment for the short and long-term. This can have a negative impact not only in terms of costs, but also employer reputation, employee morale, and productivity. Fact is, however, that onboarding today is an ongoing process and emerging practice that needs to be provided to new hires and employees on a regular basis as their roles change, they transfer to new teams, and reorganisations occur to respond to market and customer needs are the norm, rather than the exception. Moreover, the expectations of new hires today have also changed and adapted, resulting in expectations of a more personable, digital, timely and rewarding onboarding experience that facilitates success in their new roles. The current paper outlined some of these trends and raised several points that speak to these developments. First, the need to revisit the concept of onboarding as a one-shop-one-stop experience. Second, the changing nature and remit of future role and organisational expectation that new hires have, which also affect their evaluation of their onboarding experiences. And third, the need for organisations to recognition that onboarding can generate numerous mutual learning opportunities - once the right success factors for onboarding are identified and relevant human resource practices are connected to onboarding.

\section{References}

Adler, A.B. and Castro, C.A. (2019), "Transitions: a theoretical model for occupational health and wellbeing", Occupational Health Science, Vol. 3 No. 2, pp. 105-123.

Bauer, T.N. (2010), Onboarding New Employees: Maximizing Success, SHRM Foundation's Effective Practice Guidelines Series, Society for Human Resource Management, Alexandria, VA.

Benzinger, D. (2016), "Organizational socialization tactics and newcomer information seeking in the contingent workforce", Personnel Review, Vol. 45 No. 4, pp. 743-763.

Bhakta, K. and Medina, M.S. (2021), "Preboarding, orientation, and onboarding of new pharmacy faculty during a global pandemic", American Journal of Pharmaceutical Education, Vol. 85 No. 3, article 8510, doi: 10.5688/ajpe8510.

Brown, L. (2021), Two-Thirds of HR Leaders Plan to Continue Virtual Onboarding after Covid, Research Finds, People Management (UK), available at: https://www.peoplemanagement.co.uk/ news/articles/two-thirds-of-hr-leaders-plan-to-continue-virtual-onboarding-after-covid\#gref (accessed 1 August 2021).

Caldwell, C. and Peters, R. (2018), "New employee onboarding - psychological contracts and ethical perspectives", Journal of Management Development, Vol. 37 No. 1, pp. 27-39.

Caligiuri, P., De Cieri, H., Minbaeva, D., Verbeke, A. and Zimmermann, A. (2020), "International HRM insights for navigating the COVID-19 pandemic: implications for future research and practice", Journal of International Business Studies, Vol. 51 No. 5, pp. 697-713.

Cattermole, G. (2019), "Developing the employee lifecycle to keep top talent", Strategic HR Review, Vol. 18 No. 6, pp. 258-262.

Cesário, F. and Chambel, M.J. (2019), "On-boarding new employees: a three-component perspective of welcoming”, International Journal of Organizational Analysis, Vol. 27 No. 5, pp. 1465-1479. 
Chamorro-Premuzic, T., Winsborough, D., Sherman, R.A. and Hogan, R. (2016), "New talent signals: shiny new objects or a brave new world?", Industrial and Organizational Psychology, Vol. 9 No. 3, pp. 621-640.

Chao, G.T., O’Leary-Kelly, A.M., Wolf, S., Klein, H.J. and Gardner, P.D. (1994), “Organizational socialization: its content and consequences", Journal of Applied Psychology, Vol. 79 No. 5, pp. 730-743.

Chillakuri, B. (2020), "Understanding Generation Z expectations for effective onboarding”, Journal of Organizational Change Management, Vol. 33 No. 7, pp. 1277-1296.

Dekas, K. (2013), "Nooglers to Googlers: applying science and measurement to new hire onboarding", Paper Presented at the Society for Industrial and Organizational Psychology Conference, Houston, Texas.

Ellis, A.M., Nifadkar, S.S., Bauer, T.N. and Erdogan, B. (2017), "Newcomer adjustment: examining the role of managers' perception of newcomer proactive behavior during organizational socialization”, Journal of Applied Psychology, Vol. 102 No. 6, pp. 993-1001.

Garg, N., Murphy, W. and Singh, P. (2021), "Reverse mentoring, job crafting and work-outcomes: the mediating role of work engagement", Career Development International, Vol. 34 No. 5, pp. 5-8.

Gherardi, S. and Perrotta, M. (2010), "Where is induction? Profession, peer group and organization in contention", Society and Business Review, Vol. 5 No. 1, pp. 84-98.

Gratton, L. (2021), "Four principles to ensure hybrid work is productive work", MIT Sloan Management Review, Vol. 62 No. 2, pp. 11A-16A.

Gregory, C.K., Meade, A.W. and Foster Thompson, L. (2013), "Understanding internet recruitment via signaling theory and the elaboration likelihood model", Computers in Human Behavior, Vol. 29 No. 5, pp. 1949-1959.

Guðmundsdóttir, S. and Lundbergsdóttir, L.M. (2016), “Onboarding self-initiated expatriates: the case of Icelandic employees working for the Nordic Cooperation”, Journal of Workplace Learning, Vol. 28 No. 8, pp. 510-518.

Harris, C.M. and Pattie, M.W. (2020), "Interns' perceptions of HR practices and their influence on fit and intentions to join", The International Journal of Human Resource Management, Vol. 31 No. 12 , pp. 1513-1532.

Hawse, S. and Wood, L.N. (2019), "Designing workplace induction programs to support the transition of new-career engineers to practice", Higher Education, Skills and Work-Based Learning, Vol. 9 No. 1, pp. 18-29.

Horstmeier, C.A.L., Homan, A.C., Rosenauer, D. and Voelpel, S.C. (2016), "Developing multiple identifications through different social interactions at work", European Journal of Work and Organizational Psychology, Vol. 25 No. 6, pp. 928-944.

Jeske, D. and Axtell, C.M. (2018), "The nature of relationships in e-internships: a matter of psychological contract, communication and relational investment", The Journal of Work and Organizational Psychology, Vol. 34 No. 2, pp. 113-121.

Jokisaari, M. and Vuori, J. (2018), "Leaders' resources and newcomer socialization: the importance of delegation”, Journal of Managerial Psychology, Vol. 33 No. 2, pp. 161-175.

Karambelkar, M. and Bhattacharya, S. (2017), "Onboarding is a change: applying change management model ADKAR to onboarding", Human Resource Management International Digest, Vol. 25 No. 7, pp. 5-8.

Klein, H.J. and Polin, B. (2012), "Are organizations on board with best practices onboarding?", in Wanberg, C.R. (Ed.), The Oxford Handbook of Socialization, Oxford University Press, New York, NY, pp. 267-287.

Kniffin, K.M., Narayanan, J., Anseel, F., Antonakis, J., Ashford, S.P., Bakker, A.B., Bamberger, P., Bapuji, H., Bhave, D.P., Choi, V.K., Creary, S.J., Demerouti, E., Flynn, F.J., Gelfand, M.J., Greer, L.L., Johns, G., Kesebir, S., Klein, P.G., Lee, S.Y., Ozcelik, H., Petriglieri, J.L., Rothbard, N.P., Rudolph, C.W., Shaw, J.D., Sirola, N., Wanberg, C.R., Whillans, A., Wilmot, M.P. and van Vugt, M. 
JWAM

14,1
(2021), "COVID-19 and the workplace: implications, issues, and insights for future research and action", American Psychologist, Vol. 76 No. 1, pp. 63-77.

Kowtha, N.R. (2018), "Organizational socialization of newcomers: the role of professional socialization”, International Journal of Training and Development, Vol. 22 No. 2, pp. 87-106.

Link, G.J.P. and Jeske, D. (2017), "Understanding organization and open source community relations through the attraction-selection-attrition model", Conference Paper, OpenSym (13th International Symposium on Open Collaboration), 23-25 August 2017, National University of Ireland, Galway, Ireland.

Moran, G. (2019), "How to stop candidates from ghosting you after accepting the job offer", available at: https://www.fastcompany.com/90360309/how-to-stop-candidates-from-ghosting-you-afteraccepting-the-job-offer\# (accessed 1 August 2021).

Morrison, L. (2021), "Virtual improvement: advising and onboarding during a pandemic", Honors in Practice, Vol. 17 No. 2021, pp. 203-206.

Mulders, D.E.M., Berends, P.A.J., Georges, L. and Romme, A. (2010), "Dynamic capability and staff induction practices in small firms", Society and Business Review, Vol. 5 No. 2, pp. 155-169.

Odom, C.L. (2018), "How to onboard a gig employee", Society for Human Resource Management, available at: https://www.shrm.org/ResourcesAndTools/hr-topics/talent-acquisition/Pages/ How-to-Onboard-a-Gig-Employee.aspx (accessed 27 April 2021).

Rodeghero, P., Zimmermann, T., Houck, B. and Ford, D. (2021), "Please turn your cameras on: remote onboarding of software developers during a pandemic", The Proceedings of the 2021 IEEE/ ACM 43rd International Conference on Software Engineering: Software Engineering in Practice (ICSE-SEIP), IEEE, pp. 41-50, doi: 10.1109/ICSE-SEIP52600.2021.00013.

Rousseau, D.M. (1995), Psychological Contracts in Organizations: Understanding Written and Unwritten Agreements, Sage, Thousand Oaks, CA.

Schneider, B. (1987), “The people make the place”, Personnel Psychology, Vol. 40 No. 3, pp. 437-453.

Shufutinsky, A. and Cox, R. (2019), "Losing talent on day one: onboarding millennial employees in health care organizations”, Organization Development Journal, Vol. 37 No. 4, pp. 33-51.

Skeats, J. (1991), Successful Induction: How to Get the Most from Your Employees, Kogan Page, London.

Sprogoe, J. and Elkjaer, B. (2010), "Induction - organizational renewal and the maintenance of status quo", Society and Business Review, Vol. 5 No. 2, pp. 130-143.

Steer, D. (2013), "Onboard with it all. Eleven ways to ensure your onboarding program accomplishes everything it's supposed to", $T+D$ November, pp. 26-29.

Stewart, J., Jones, J. and Vallas, S. (2021), "How employee onboarding will change in a post-pandemic hybrid workplace", available at: https://www.willistowerswatson.com/en-CA/Insights/2021/03/ how-employee-onboarding-will-change-in-a-post-pandemic-hybrid-workplace (accessed 1 August 2021).

Tharenou, P. and Kulik, C.T. (2020), "Skilled migrants employed in developed, mature economies: from newcomers to organizational insiders", Journal of Management, Vol. 46 No. 6, pp. 1156-1181.

Zung, R. (2020), The Longtail of the Pandemic on Onboarding and Orientation, HR Daily Advisor, available at: https:/hrdailyadvisor.blr.com/2020/07/29/the-longtail-of-the-pandemic-ononboarding-and-orientation/(accessed 1 August 2021).

\section{Corresponding author}

Debora Jeske can be contacted at: d.jeske@ucc.ie

For instructions on how to order reprints of this article, please visit our website:

www.emeraldgrouppublishing.com/licensing/reprints.htm

Or contact us for further details: permissions@emeraldinsight.com 